\title{
Mental adaptation to cancer in women with gynaecological cancer
}

\author{
Ewa Kupcewicz' , Joanna Olewińska', Hanna Pikus², Marcin Jóźwik³ \\ ${ }^{1}$ Department of Nursing, Faculty of Health Sciences, Collegium Medicicum University of Warmia and Mazury in Olsztyn, \\ Poland \\ ${ }^{2}$ Department of Multimedia and Computer Graphics, Faculty of Mathematics and Information Technology, University of \\ Warmia and Mazury in Olsztyn, Poland \\ ${ }^{3}$ Department of Gynecology and Obstetrics, School of Medicine, Collegium Medicicum University of Warmia and Mazury \\ in Olsztyn, Poland
} Kupcewicz E, Olewińska J, Pikus H, Jóźwik M. Mental adaptation to cancer in women with gynaecological cancer. J Pre-Clin Clin Res. 2017;
11(2): 120-126. doi: $10.26444 / j p c c r / 80986$

\begin{abstract}
Introduction and objective. Adapting to gynaecological cancer is the problem of accepting and coping with the disease and its consequences. The aim of this study is to analyze the relationship between stress intensity and strategies for coping with stress and psychological adaptation to disease in women diagnosed with gynaecological cancer.

Materials and method. The study was performed on a group of 102 women diagnosed with gynaecologic malignancy. The mean age of patients was 56.1 (SD \pm 10.75 ) years. Three self- designed questionnaires were used to carry out the study: Scale of Perceived Stress (PSS-10), Multidimensional Inventory for Measuring Coping with Stress (Mini-COPE) and the Scale of Mental Adaptation to Cancer (Mini-MAC). Statistical significance was set at $p<0.05$.

Results. In more than half of the women surveyed, the severity of stress experienced during the last month was high. Women with a malignant illness significantly differed $(p<0.001)$ in the styles of coping with the disease, preferring a constructive style $(M=43.5 ; S D \pm 5.76)$ rather than a destructive style $(M=21.7 ; S D \pm 5.28)$. The highest median values were obtained by positive revalidation $(M=21.9 ; S D \pm 3.01)$ and fighting spirit $(M=21.6 ; S D \pm 3.47)$ strategies. The most prominent indicator of predicting a constructive style of coping with cancer was the coping strategy described as Positive Revalidation $\left(\right.$ (Beta $\left.=0.38 ; R^{2}=0.41\right)$; whereas an Acceptance strategy was a predictor of a destructive style (ßeta=-0.30; $R^{2}=0.31$ ).

Conclusions. Most women facing gynaecological cancer experience a high level of stress, and try to use active strategies to deal with the disease. The results indicate that there is a need to offer special psychological care to oncologically diagnosed women.
\end{abstract}

\section{Key words}

mental adaptation, stress, coping strategies, cancer

\section{INTRODUCTION}

Ways of defining and understanding the notion of stress, as well as of coping with stress, have been analyzed in the literature by numerous researchers. The concept of stress, according to $\mathrm{H}$. Selye, has been described as 'a non-specific reaction of the body to all demands, and therefore not only the ones that are threatening to humans'. In this case, stress is understood as an organism's reaction to an event, with its physiological and psychological consequences $[1,2]$. On the other hand, R. Lazarus and S. Folkman refer to the transactional approach to stress, assuming that stress is a disturbance of the interaction between an individual and the environment. For the individual, not only is the event itself important, but also how it is perceived and interpreted [3-5]. According to the authors, coping means 'constantly changing cognitive and behavioral efforts to master specific external and internal demands that the person perceives as being excessive or overburdening' $[1,5-7]$. In the face of disease, people behave in an individual way known as the style of coping. The reason for this is the individual differences that

Adress for correspondence: Ewa Kupcewicz, Faculty of Health Sciences, Department of Nursing, Collegium Medicicum University of Warmia and Mazury in Olsztyn, Poland, Żołnierska 14C, 10-561 Olsztyn, Poland

E-mail: ekupcewicz@wp.pl

Received: 1 November 2017; accepted: 5 December 2017 manifest in the condition of the illness and are due to the individual's character and to the significance attributed by them to the external situation $[1,8]$. Parker and Endler have distinguished three forms of behaviour in a stressful situation: a task-focused style (in which an individual takes action to solve the problem using cognitive processing), an emotional-focused style (in which a person is focused on their own emotional experiences), and a style focused on avoidance (in which one rejects thoughts of the fundamental problem) [7-9]. Carver et al., referring to the theory of Lazarus, pointed to the availability and situational coping with stress. In the first case, 'dispositional coping' is understood as a relatively constant, individual-specific tendency that sets the course of coping with stress. In the second case, the methods used by the individual in a particular stressful situation were identified as 'situational coping'. An individual has a pool of coping strategies and their choice is determined both by the individual's personality and the situation $[1,8,10-11]$.

Observation of the first symptoms of cancer begins the process of struggling with a disease that is associated with various ailments [8]. Particularly strong stress is observed in gynaecologic malignancies associated with surgical treatment, as well as radio- and chemotherapy treatment. In the literature, a phenomenon of adapting to cancer is of interest to many researchers. An example is the study by Watson et al. concerning oncological patients. In that paper, 
a scale for the study of mental adaptation to cancer was described. It measures four strategies of coping with illness: anxiety absorption, helplessness-hopelessness, fighting spirit, and positive revalidation [12-13]. Intercorrelation between the studied strategies has shown that there are two different styles of coping with the malignant disease. The first one is passive and destructive, including non-adaptive behaviour, and is represented by anxiety absorption and helplessnesshopelessness. The second strategy is active and constructive, i.e. related to adaptive behaviour, and is characterized by a fighting spirit and positive revalidation [8, 12-13]. A review of many studies of oncologically ill patients justifies multidimensional approaches to their adaptation [14-18].

\section{OBJECTIVE}

The aim of the study was to investigate a possible link between preferred strategies for coping with stress and stress intensity, as well as to identify predictors of styles for coping with cancer in a group of women after hysterectomy.

\section{MATERIALS AND METHOD}

The study group included 102 women with a histopathological diagnosis of ovarian (endometrial: $n=96$; cervical: $n=6$ ) cancer after surgical treatment, hospitalized in the oncological gynecology departments located in hospitals in Olsztyn, north-eastern Poland, between January, 2015 - April, 2016. Respondents were informed about the purpose of the study and the confidentiality of data. They had the opportunity to ask questions and receive replies and explanations. All the respondents gave their consent to participate in the study. A diagnostic survey was used as a research method. Stress intensity in the study group was estimated using the Perceived Stress Scale (PSS-10 by: S. Cohen, T. Kamarck, $R$. Mermelstein). The Polish adaptation was performed by Z Juczynski and N. Oginska-Bulik. The scale was used to assess the intensity of stress related to a patient's situation within the last month. The scale contains 10 questions about the different subjective perceptions of personal problems and events, behaviours and coping strategies. The respondents assessed every question using a five-point scale by assigning answers ranging from $0-4$ points according to the following scores: 0 - never, 1 - almost never, 2 - sometimes, 3 - quite often, 4 - very often. The overall score was the sum of all points, with a distribution from $0-40$. The higher the score, the greater the intensity of the stress experienced. The PSS-10 has satisfactory psychometric properties [1]. Measurement of strategies for coping with cancer was performed using the Mini-MAC scale (by M. Watson, M. Law, M. dos Santos, S. Greer, J. Baruch, J. Bliss). The Polish adaptation was performed by Z. Juczynski. The Polish version of the Mini-Mac scale includes 29 statements and measures four coping strategies: anxiety absorption, fighting spirit, helplessness-hopelessness, and positive revalidation. The strategies of fighting spirit and positive revalidation represent a constructive style, and the strategies of absorbing anxiety and helplessness-hopelessness represent a destructive style of coping with cancer. The respondent assessed to what extent the statements related to them at the moment in a four-step scale. The possible answers were as follows: 1 - definitely not, 2 - not quite,
3 - rather yes, 4 - definitely yes. Results were calculated separately for each strategy. Each strategy consisted of 7 statements. The range of possible outcomes for each of the four strategies ranged from $7-28$ points. The higher the score, the higher the level of behaviour that characterizes a particular way of coping with cancer. The Mini-MAC scale is known for its good psychometric properties. In Polish studies, high Cronbach alpha coefficients were obtained for the helplessness-hopelessness strategy (0.92), fighting spirit strategy (0.90) as well as slightly lower coefficients for anxiety absorption (0.89) and positive reevaluation strategies (0.87) [8].

A shortened version of the Multidimensional Inventory for Measuring Coping with Stress (COPE, by C.S Carver, M.F. Scheier and J.K. Weintraub) was used to measure the coping strategies. It was named Mini-COPE, in the Polish adaptation by Juczynski and Oginska-Bulik. The questionnaire contains 28 statements that form part of 14 strategies for coping with stress. According to the recommendations of the authors of the questionnaire, a modified version of the scale has been applied to oncological patients and included 13 strategies: Active Coping, Planning, Positive Revalidation, Acceptance, Sense of Humour, Turn to Religion, Seeking Emotional Support from Partner, Seeking Emotional Support from Friends, Taking Care of Something Else, Denial, Use of Psychoactive Substances, or Cessation of Activities. Every study participant was to select one of four possible answers for each statement, indicating the degree of severity of the analyzed parameters: 0 - I almost never do that, 1 - I rarely do that, 2 - I often do, 3 - I almost always do. Each strategy was evaluated separately, adding points to the answers for the two statements that made up its composition, and dividing the sum by two. The spread of each strategy's results was in the range of $0-3$. The psychometric properties of the Polish version of the Mini-COPE inventory are similar to the original version [1].

Statistical analysis. Statistical calculations were performed using the STATISTICA 12 package. Descriptive statistics were used to analyze the data. The overall intensity index of perceived stress was transformed into standardized units, which were interpreted according to the Sten scale, a standardized psychological test scale. The scale contains 10 units and the step in the scale equals 1 sten. Stens $1-4$ indicate a low result, while a range of $7-10$ is considered to be a high result [1]. Evaluation of the values of the characteristics tested in the class of clustering variables was performed using the ANOVA test (F) of repeated measurements. Correlation relationships between variables were determined using a Spearman's (R) rank correlation coefficient. For constructing the regression model, the best subset of the highest R-square statistics method was used. A p statisitc $<0.05$ was considered significant.

\section{RESULTS}

Characteristics of the study group. The study group included 102 women with a histopathological diagnosis of genital cancer (94.1\% endometrial cancer; $5.9 \%$ cervical cancer), aged $28-80$, with an average age of 56.10 ( \pm SD 10.75) and a median age of 56.5 years. They were mainly women living in the city $(n=74 ; 72.6 \%)$, married $(n=68 ; 66.7 \%)$, with a 
secondary education $(\mathrm{n}=43 ; 42.2 \%)$, professionally active $(n=39 ; 38.2 \%)$, as well as retired $(n=35 ; 34.3 \%)$. Nearly $1 / 3$ of the respondents had been suffering from this disease for two or three years. Detailed characteristics of the respondents are shown in Table 1.

Table 1. Characteristics of respondents.

\begin{tabular}{|c|c|c|}
\hline Variables & & $\mathrm{N}=102(\%)$ \\
\hline \multirow{5}{*}{ Age (in years) } & $M=56.1 ; S D=10.75$ & \\
\hline & $<=50$ years & $33(32.3)$ \\
\hline & $51-60$ & $30(29.4)$ \\
\hline & $61-70$ & $31(30.4)$ \\
\hline & $71=>$ years & $8(7.9)$ \\
\hline \multirow[t]{2}{*}{ Place of residence } & City & $74(72.5)$ \\
\hline & Town & $28(27.5)$ \\
\hline \multirow{4}{*}{ Marital status } & Married & $68(66.7)$ \\
\hline & Widowed & 18(17.6) \\
\hline & Divorced & $11(10.8)$ \\
\hline & Single & $5(4.9)$ \\
\hline \multirow[t]{4}{*}{ Education } & Primary & $16(15.7)$ \\
\hline & Vocational & $16(15.7)$ \\
\hline & Secondary & $43(42.1)$ \\
\hline & Higher & $27(26.5)$ \\
\hline \multirow{4}{*}{ Socio-professional status } & Professionally active & $39(38.2)$ \\
\hline & Unemployed & $13(12.8)$ \\
\hline & Retired & $35(34.3)$ \\
\hline & Pensioner & $15(14.7)$ \\
\hline \multirow[t]{5}{*}{ Time since diagnosis of cancer } & $<=6$ months & $26(25.5)$ \\
\hline & 7-24 months & $17(16.7)$ \\
\hline & $2-3$ years & $30(29.4)$ \\
\hline & $4-5$ years & 17(16.6) \\
\hline & $6=>$ years & $12(11.8)$ \\
\hline \multirow[t]{3}{*}{ Presence of coexisting illnesses } & no coexisting illnesses & $33(32.4)$ \\
\hline & one coexisting illness & $39(38.2)$ \\
\hline & two or more coexisting illnesses & $30(29.4)$ \\
\hline \multirow[t]{2}{*}{ BMI $\left(\mathrm{kg} / \mathrm{m}^{2}\right)$} & normal $(<30)$ & $38(37.3)$ \\
\hline & above normal $(>=30)$ & $64(62.7)$ \\
\hline \multirow[t]{3}{*}{ Support from family/friends } & always received & $80(78.4)$ \\
\hline & received sporadically & $17(16.7)$ \\
\hline & no suport & $5(4.9)$ \\
\hline
\end{tabular}

$\mathrm{N}$ - number; $\mathrm{M}$ - arithmetic average; SD - standard deviation

Applied strategies/styles of coping with cancer. Analysis of ANOVA variance of repeated measurements showed statistically significant differences between strategies of mental adaptation to cancer in the study group $(\mathrm{F}=48.11$; $\mathrm{p}<0.001)$. The highest mean values were obtained by two active strategies: positive revalidation strategy $(\mathrm{M}=21.9$; $\mathrm{SD} \pm 3.01$ ), representing a re-organization of the problem of the disease, and the fighting spirit strategy $(M=21.6$; $\mathrm{SD} \pm 3.47$ ), prompting the patient to treat the disease as a personal challenge and take action against it. The next two destructive strategies were: anxiety absorption $(M=19.1$; $\mathrm{SD} \pm 4.90)$ and helplessness-hopelessness $(\mathrm{M}=15.7 ; \mathrm{SD} \pm 4.67)$. They had significantly lower mean values. Statistical analyses have shown that women suffering from serious illness differ significantly in their coping styles $(\mathrm{F}=556.42 ; \mathrm{p}<0.001)$. The constructive style $(M=43.5 ; \mathrm{SD} \pm 5.76)$ had significantly higher values than the destructive style ( $M=21.7 ; \mathrm{SD} \pm 5.28)$ (Tab. 2). This means that the patients use their resources and mobilize to actively tackle problems and try to remove the source of stress or reduce the force of its impact.

An analysis of ANOVA variance of repetitive measurements was also performed for stress management strategies that revealed statistically significant differences $(\mathrm{F}=64.95$; $\mathrm{p}<0.001)$ in the study group. A comparison of the mean values of the strategies studied in Table 2 shows that the highest value is found in the Seeking Emotional Support from Partner strategy $(\mathrm{M}=2.02$; $\mathrm{SD} \pm 0.84)$, followed by the Active Coping strategy $(M=1.95 ; S D \pm 0.60)$, Seeking Emotional Support from Friends $(\mathrm{M}=1.87 ; \mathrm{SD} \pm 0.64)$ and Taking Care of Something Else strategy $(\mathrm{M}=1.86 ; \mathrm{SD} \pm 0.69)$, which involves dealing with various activities allowing a patient to forget about their illness. Statistical analysis showed that the overall mean score for the perceived stress scale PSS-10 was $21.0(\mathrm{SD} \pm 5.76)$ in female patients. After transforming into standardized units and according to stenographic features, $65.7 \%(n=67)$ of patients were found to have high stress levels, $23.5 \%(n=24)$ of patients had an average stress level, and a low stress level was found in only $10.8 \%(n=11)$ of patients. It should be concluded that women with gynecological cancer assess their own situation as stressful, unpredictable or overly burdensome.

Table 2. Intensity of stress and the strategies/styles of coping with stress/ illness in the study group $\mathrm{N}=102$

\begin{tabular}{|c|c|c|c|c|}
\hline \multicolumn{2}{|c|}{ Variables } & M & SD & $\begin{array}{c}\text { ANOVA } \\
\text { test value (F) } \\
p \text { value }\end{array}$ \\
\hline \multicolumn{5}{|c|}{ Coping with disease strategies (Mini - MAC) } \\
\hline & Anxiety absorption & 19.1 & 4.90 & \multirow{4}{*}{$\begin{array}{l}F=48.11 \\
p<0.001\end{array}$} \\
\hline 2. & Fighting spirit & 21.6 & 3.47 & \\
\hline 3. & Helplessness/hopelessness & 15.7 & 4.67 & \\
\hline 4. & Positive revalidation & 21.9 & 3.01 & \\
\hline \multicolumn{5}{|c|}{ Styles of coping with illness (Mini - MAC) } \\
\hline 1. & Constructive style & 43.5 & 5.76 & \multirow{2}{*}{$\begin{array}{c}F=556.42 \\
p<0.001\end{array}$} \\
\hline 2. & Destructive style & 21.7 & 5.28 & \\
\hline \multicolumn{5}{|c|}{ Coping with stress strategies (Mini - COPE) } \\
\hline 1. & Active coping & 1.95 & 0.60 & \multirow{13}{*}{$\begin{array}{l}F=64.95 \\
p<0.001\end{array}$} \\
\hline 2. & Planning & 1.85 & 0.62 & \\
\hline 3. & Positive revalidation & 1.52 & 0.89 & \\
\hline 4. & Acceptance & 1.71 & 0.76 & \\
\hline 5. & Sense of humor & 0.76 & 0.71 & \\
\hline 6. & Turn toward religion & 1.76 & 0.94 & \\
\hline 7. & Seeking Emotional Support From Partner & 2.02 & 0.84 & \\
\hline 8. & Seeking Emotional Support From Friends & 1.87 & 0.64 & \\
\hline 9. & Taking Care of Something Else & 1.86 & 0.69 & \\
\hline 10. & Denial & 1.38 & 0.61 & \\
\hline 11. & Discharge & 1.59 & 0.54 & \\
\hline 12. & Use of Psychoactive Substances & 0.28 & 0.57 & \\
\hline 13. & Cessation of Actions & 1.01 & 0.77 & \\
\hline \multicolumn{2}{|c|}{ Intensity of the perceived stress (PSS-10) } & 21.0 & 5.76 & \\
\hline
\end{tabular}

Statistically significant: $p<0.05 ; p<0.01 ; p<0.001$

Explanation: $\mathrm{N}$-number, $\mathrm{M}$ - arithmetic average, $\mathrm{SD}$ - standard deviation 
Intensity of experienced stress and strategies/styles of coping with illness. In own studies, the relationship between the intensity of stress experienced by a sick woman and the strategies of dealing with gynecological cancer was sought. Spearman's rank correlation coefficient was used in statistical analysis, and interpretation of the relationship between variables was based on Guilford's classification.

Table 3. Spearman's correlation coefficients $(R)$ between stress intensity and strategies for coping with cancer $(\mathrm{N}=102)$

\begin{tabular}{lcc}
\hline $\begin{array}{l}\text { Strategies for coping with illness } \\
\text { (Mini - MAC) }\end{array}$ & \multicolumn{2}{c}{$\begin{array}{c}\text { Experienced stress intensity } \\
\text { (PSS-10) }\end{array}$} \\
\cline { 2 - 3 } & $\mathrm{R}$ & $\mathrm{p}$ \\
\hline Anxiety absorption & 0.65 & 0.001 \\
\hline Fighting spirit & -0.55 & 0.001 \\
\hline Helplessness/hopelessness & 0.65 & 0.001 \\
\hline Positive revalidation & -0.44 & 0.001
\end{tabular}

The analysis showed a statistically significant, strong negative correlation between the intensity of stress experienced by the studied women and the fighting spirit strategy $(\mathrm{R}=-0.55 ; \mathrm{p}<0.001)$, and a significant negative correlation between the intensity of the stress experienced and the positive reevaluation strategy $(\mathrm{R}=-0.44 ; \mathrm{p}<0.001)$ (Table 3). It should be pointed out that low stress levels allow patients to take action to improve their own situation, and more often choose active strategies to deal with the disease. Statistical calculations show that there is a significant, strong positive correlation between the intensity of stress experienced by women with gynaecological cancer and strategies such as anxiety absorption $(\mathrm{R}=0.65 ; \mathrm{p}<0.001)$ and helplessness $(\mathrm{R}=0.65 ; \mathrm{p}<0.001)$ (Table 3$)$. It can be concluded that the combination of high stress and more frequent use of passive strategies is associated with poor prognosis, manifested by the worst mental adaptation to cancer in the examined women. Further analysis showed that the level of stress experienced in the group of women with gynaecological cancer significantly influenced the style of coping with the disease.

Table 4. Spearman's correlation coefficient (R) between the intensity of stress experienced and the styles of coping with cancer $(\mathrm{N}=102)$

\begin{tabular}{lcc}
\hline $\begin{array}{l}\text { Styles of coping with illness } \\
\text { (Mini - MAC) }\end{array}$ & \multicolumn{2}{c}{ Degree of stress intensity (PSS-10) } \\
\cline { 2 - 3 } & $\mathrm{R}$ & $\mathrm{p}$ \\
\hline Constructive style & -0.55 & 0.001 \\
\hline Destructive style & 0.66 & 0.001 \\
\hline
\end{tabular}

The results presented in Table 4 indicate that there is a significant, strong negative correlation $(\mathrm{R}=-0.55$; $\mathrm{p}<0.001)$ between the intensity of stress experienced in the studied women and the constructive style of coping with cancer. There was also a significant, strong positive correlation $(\mathrm{R}=0.66 ; \mathrm{p}<0.001)$ between the intensity of stress experienced in the studied women and the destructive style of coping with the disease. The results of the presented study confirm that patients with gynaecologic malignancies who experience high levels of stress simultaneously reveal higher anxiety overload, greater helplessness and less willingness to fight.
Relationship between strategies for coping with stress and strategies/styles of coping with illness. In further analysis, relationships were also sought in coping strategies identified under Mini-COPE with the Mini-MAC disease management styles/strategies. Spearman's correlation coefficient was used to clarify this issue. The obtained results are complex, revealing significant differences in the course of the coping processes.

Table 5. Spearman's correlation coefficients $(R)$ between strategies for coping with stress and styles of coping with illness $(\mathrm{N}=102)$

\begin{tabular}{|c|c|c|c|c|c|c|c|c|}
\hline \multirow{3}{*}{$\begin{array}{l}\text { Strategies for } \\
\text { coping with stress } \\
\text { (Mini - COPE) }\end{array}$} & \multicolumn{8}{|c|}{ Style of coping with illness (Mini - MAC) } \\
\hline & \multicolumn{2}{|c|}{$\begin{array}{c}\text { Anxiety } \\
\text { absorption }\end{array}$} & \multicolumn{2}{|c|}{$\begin{array}{l}\text { Fighting } \\
\text { Spirit }\end{array}$} & \multicolumn{2}{|c|}{$\begin{array}{l}\text { Helplessness - } \\
\text { hopelessness }\end{array}$} & \multicolumn{2}{|c|}{$\begin{array}{c}\text { Positive } \\
\text { Revalidation }\end{array}$} \\
\hline & $\mathrm{R}$ & $\mathrm{p}$ & $\mathrm{R}$ & $\mathrm{p}$ & $\mathrm{R}$ & $\mathrm{p}$ & $\mathrm{R}$ & $\mathrm{p}$ \\
\hline Active Coping & -0.25 & 0.01 & 0.44 & 0.001 & -0.42 & 0.001 & 0.52 & 0.001 \\
\hline Planning & -0.14 & 0.13 & 0.29 & 0.003 & -0.35 & 0.001 & 0.40 & 0.001 \\
\hline $\begin{array}{l}\text { Positive } \\
\text { Revalidation }\end{array}$ & -0.55 & 0.001 & 0.61 & 0.001 & -0.59 & 0.001 & 0.54 & 0.001 \\
\hline Acceptance & -0.58 & 0.001 & 0.63 & 0.001 & -0.63 & 0.001 & 0.44 & 0.001 \\
\hline Sense of Humor & -0.59 & 0.001 & 0.56 & 0.001 & -0.54 & 0.001 & 0.18 & 0.07 \\
\hline $\begin{array}{l}\text { Turn Towards } \\
\text { Religion }\end{array}$ & 0.03 & 0.76 & 0.10 & 0.29 & -0.01 & 0.884 & 0.54 & 0.001 \\
\hline $\begin{array}{l}\text { Seeking Emotional } \\
\text { Support From } \\
\text { Partner }\end{array}$ & -0.07 & 0.46 & 0.24 & 0.01 & -0.31 & 0.01 & 0.46 & 0.001 \\
\hline $\begin{array}{l}\text { Seeking Emotional } \\
\text { Support From } \\
\text { Friends }\end{array}$ & -0.13 & 0.17 & 0.17 & 0.09 & -0.22 & 0.03 & 0.44 & 0.001 \\
\hline $\begin{array}{l}\text { Taking Care of } \\
\text { Something Else }\end{array}$ & -0.38 & 0.001 & 0.53 & 0.001 & -0.42 & 0.001 & 0.38 & 0.001 \\
\hline Denial & -0.15 & 0.13 & 0.17 & 0.08 & -0.10 & 0.324 & 0.14 & 0.17 \\
\hline Discharge & 0.03 & 0.71 & 0.16 & 0.11 & -0.02 & 0.847 & 0.10 & 0.30 \\
\hline $\begin{array}{l}\text { Use of } \\
\text { Psychoactive } \\
\text { Substances }\end{array}$ & -0.02 & 0.79 & -0.13 & 0.17 & 0.06 & 0.525 & -0.18 & 0.07 \\
\hline $\begin{array}{l}\text { Cessation of } \\
\text { Actions }\end{array}$ & 0.31 & 0.001 & -0.40 & 0.000 & 0.47 & 0.000 & -0.33 & 0.001 \\
\hline
\end{tabular}

The results of the study show that there is a statistically significant negative correlation between the stress coping strategies described as Sense of Humour $(\mathrm{R}=-0.59 ; \mathrm{p}<0.001)$, Acceptance $(\mathrm{R}=-0.58 ; \mathrm{p}<0.001)$, Positive Revalidation $(\mathrm{R}=-$ $0.55 ; \mathrm{p}<0,001)$, Taking care of Something Else $(\mathrm{R}=-0.38$; $\mathrm{p}<0.001)$ and Active Coping $(\mathrm{R}=-0.25 ; \mathrm{p}<0.01)$, and the passive anxiety-absorbing strategy expressing anxiety associated with the disease (Tab. 5). There was also a significant positive correlation between the Cessation of Actions strategy $(\mathrm{R}=0.31 ; \mathrm{p}<0.001)$ and anxiety absorption observed. It is worth noting that there were also evasive strategies in the array of methods used. It can be concluded, that in the coping process, the surveyed women chose strategies depending on the situation in relation to specific occurrences. In the current study, a relationship was confirmed between the Fighting Spirit strategy (high, positive correlation) and strategies for coping with stress, such as: Acceptance $(\mathrm{R}=0.63 ; \mathrm{p}<0.001)$, Positive Revalidation $(\mathrm{R}=0.61$; $\mathrm{p}<0.001)$, Sense of Humour $(\mathrm{R}=0.56 ; \mathrm{p}<0.001)$ and Taking Care of Something Else $(\mathrm{R}=0.53 ; \mathrm{p}<0.001)$. The strategy of Fighting Spirit also strongly positively correlated with the Active Coping strategy $(\mathrm{R}=0.44 ; \mathrm{p}<0.001)$, and poorly 
correlated with the Planning $(\mathrm{R}=0.29 ; \mathrm{p}<0.003)$ and Seeking Emotional Support From Partner strategies $(\mathrm{R}=0.24 ; \mathrm{p}<0.01)$. All the correlations were statistically significant. In addition, the strategy for coping with illness identified as Positive Revalidation correlated positively with eight strategies for coping with stress, among them a high correlation was found in the Turn Towards Religion strategy $(\mathrm{R}=0.54, \mathrm{p}<0.001)$, Positive Revalidation $(\mathrm{R}=0 ; 54, \mathrm{p}<0.001)$ and Active Coping $(\mathrm{R}=0.52 ; \mathrm{p}<0.001)$ (Tab. 5). The Cessation of Actions strategy significantly negatively correlated with the Fighting Spirit and Positive Revalidation strategies $(R=-0.40 ; \mathrm{p}<0.000$ vs. $\mathrm{R}=-0.33 ; \mathrm{p}<0.001$, respectively). In this study, the relationship between applied styles of coping with the disease and the type of coping with stress strategies used was also analyzed.

Table 6. Spearman's correlation coefficients (R) between coping with stress strategies and coping with illness styles $(\mathrm{N}=102)$

\begin{tabular}{lcccc}
\hline \multirow{2}{*}{$\begin{array}{l}\text { Strategies for coping with stress (Mini } \\
\text { COPE) }\end{array}$} & \multicolumn{4}{c}{ Style of coping with illness (Mini - } \\
\cline { 2 - 5 } & Constructive & Destructive \\
\cline { 2 - 5 } & $\mathrm{R}$ & $\mathrm{p}$ & $\mathrm{R}$ & $\mathrm{p}$ \\
\hline Active Coping & 0.56 & 0.001 & -0.30 & 0.001 \\
\hline Planning & 0.39 & 0.001 & -0.18 & 0.07 \\
\hline Positive Revalidation & 0.65 & 0.001 & -0.58 & 0.001 \\
\hline Acceptance & 0.60 & 0.001 & -0.59 & 0.001 \\
\hline Sense of Humor & 0.41 & 0.001 & -0.58 & 0.001 \\
\hline Turn Towards Religion & 0.33 & 0.001 & 0.04 & 0.69 \\
\hline Seeking Emotional Support From Partner & 0.40 & 0.001 & -0.11 & 0.28 \\
\hline Seeking Emotional Support From Friends & 0.35 & 0.001 & -0.17 & 0.10 \\
\hline Taking Care of Something Else & 0.53 & 0.001 & -0.41 & 0.001 \\
\hline Denial & 0.17 & 0.080 & -0.15 & 0.14 \\
\hline Discharge & 0.14 & 0.175 & 0.01 & 0.89 \\
\hline Use of Psychoactive Substances & -0.18 & 0.066 & -0.02 & 0.85 \\
\hline Cessation of Actions & -0.41 & 0.001 & 0.34 & 0.001 \\
\hline
\end{tabular}

In the patients studied, the declared constructive style of coping with cancer was highly significant and positively correlated with the stress management strategies, including Positive Revalidation $(\mathrm{R}=0.65 ; \mathrm{p}<0.001)$, Acceptance $(\mathrm{R}=0.60$; $\mathrm{p}<0.001)$ and Active Coping $(\mathrm{R}=0.56 ; \mathrm{p}<0.001)$, and negatively correlated with the Cessation of Actions strategy $(\mathrm{R}=-0.41$; $\mathrm{p}<0.001$ ) (Tab. 6). The results obtained showed that Positive Revalidation and Acceptance strategies can act as adaptive strategies in situations where active coping is effective, while Active Coping strategies can be treated as a problem-focused strategy. These results (Tab. 6) show that the destructive style of coping with illness represented by the helplessnesshopelessness and the anxiety absorption strategies correlate negatively with the coping with stress strategy at statistically significant levels, i.e. Acceptance $(\mathrm{R}=-0.59 ; \mathrm{p}<0.001)$, Positive Revalidation $(\mathrm{R}=-0.58 ; \mathrm{p}<0.001)$, Active Coping $(\mathrm{R}=-0.30$; $\mathrm{p}<0.001)$ Cessation of Actions $(\mathrm{R}=0.34 ; \mathrm{p}<0.001)$.

Predictors of mental adaptation to cancer. An attempt was made to identify strategies that had a real impact on the use of constructive and destructive styles of coping with the disease within 13 strategies for coping with stress. For the construction of the regression model, the best subset of the highest R-square statistics method was implemented. As shown in Table 7, predictors of a constructive style in the women studied were three coping strategies, explaining the $56 \%$ total variance of the dependent variable. The Positive Revalidation strategy had the largest predicted share (41\%) $\left(\beta e t a=0.38 ; \mathrm{R}^{2}=0.41\right)$. This means that in the event of a disease, frequent attempts at perceiving values for development increase the likelihood of a constructive style of coping with cancer. The Acceptance and Turn to Religion Strategy also proved to be constructive style predictors, but their share in the prediction of this variable was significantly lower (15\% in total).

Table 7. Regression summary - constructive style predictors (Mini - MAC) Constructive style predictors

\begin{tabular}{lcccccc}
\hline Variables & $\mathrm{R}^{2}$ & Beta & $\mathrm{B}$ & Error $\beta$ & $\mathrm{t}$ & $p$-value \\
\hline Positive Revalidation & 0.41 & 0.38 & 2.5 & 0.55 & 4.5 & 0.00002 \\
\hline Acceptance & 0.49 & 0.34 & 2.6 & 0.63 & 4.1 & 0.0001 \\
\hline Turn To Religion & 0.56 & 0.28 & 1.7 & 0.42 & 4.0 & 0.0001 \\
\hline Constant Value & & & 32.3 & 1.14 & 28.3 & 0.0001 \\
\hline
\end{tabular}

$\mathrm{R}=0.64 ; \mathrm{R}^{2}=0.41 ;$ corrected $\mathrm{R}^{2}=0.41$

$\mathrm{R}$ - correlation coefficient, $\mathrm{R}^{2}$ - coefficient of multiple determination, Beta - standardized regression coefficient, $\mathrm{B}$ - non-standardized regression coefficient, error $\mathrm{B}$ - error of nonstandardized regression coefficient, $\mathrm{t}-\mathrm{t}$ test value

Four strategies for coping with stress, which together account for $47 \%$ of variation in results (Tab. 8), have been identified as predictors of the destructive style of coping with illness. The greatest share in the prediction of a destructive style $(31 \%)$ is the tendency 'to accept the present situation as irreversible', 'something to get used to' and 'to learn to live with' ( $\beta$ eta $=-0.30 ; \mathrm{R}^{2}=0.31$ ). It can be concluded that there is a confrontation of the threat with the individual's countermeasures. A less important contribution to the prediction of this style of coping with illness is bound to the strategy of coping with the stress associated with a Sense of Humour (9\%). The remaining two variables (Positive Revalidation and Discharge) have a limited (no more than $7 \%$ ) share in predicting the intensity of the destructive style.

Table 8. Regression summary - destructive style predictors (Mini - MAC) Destructive style predictors

\begin{tabular}{lcccccc}
\hline Variables & $\mathrm{R}^{2}$ & Beta & $\beta$ & Error $\beta$ & $\mathrm{t}$ & $\mathrm{p}$-value \\
\hline Acceptance & 0.31 & -0.30 & -2.1 & 0.67 & -3.1 & 0.002 \\
\hline Sense of Humor & 0.40 & -0.28 & -2.1 & 0.69 & -3.1 & 0.003 \\
\hline Positive Revalidation & 0.43 & -0.25 & -1.5 & 0.58 & -2.6 & 0.01 \\
\hline Discharge & 0.47 & 0.19 & 1.9 & 0.74 & 2.5 & 0.01 \\
\hline Constant value & & & 26.2 & 1.41 & 18.5 & 0.000001
\end{tabular}

$\mathrm{R}=0.69 ; \mathrm{R}^{2}=0.47$; corrected $\mathrm{R}^{2}=0.47$

\section{DISCUSSION}

Data from the presented study showed that $65.7 \%$ of women experienced high stress levels and the highest mean values were in positive revalidation $(M=21.9)$ and fighting spirit $(M=21.6)$ strategies, respectively. These results were very similar to the three standard clinical trials: Women with breast cancer $(M=20.91$ vs. $M=19.34)$, cancer of the reproductive system $(M=22.85$ vs. $M=21.59)$ and men with 
prostate cancer $(\mathrm{M}=22.30$ vs. $\mathrm{M}=23.90)$ [8]. It is worth pointing out that in the normalization studies, relatively low values for positive revalidation and fighting spirit strategies were reported in patients with gastric cancer $(M=16.96$ vs. $M=17.22)$, pancreatic cancer $(M=16.16$ vs. $M=16.31)$, and intestinal cancer $(\mathrm{M}=17.19$ vs. $\mathrm{M}=19.37)$ [8]. On the other hand, a study by Czerw et al. in a group of 238 patients diagnosed with colorectal carcinoma showed that the most commonly followed ways of mental adjustment to cancer were fighting spirit $(M=23.42)$ and positive revalidation $(M=22.31)$ [19]. The results of the presented study provide evidence that among the patients with gynaecologic malignancy there was a prevailing tendency to take active behaviours. In the face of incurable disease, the use of a constructive style is more beneficial than passive coping. Oniszczenko and Laskowska analyzed 150 adult patients with cancer. They found a relationship between emotional reactivity and coping style on the one hand, and the intensity of symptoms of trauma on the other. The study showed that individual coping style is what most strongly determines the intensity of traumarelated symptoms. The authors suggest that a constructive coping style and low emotional reactivity may act as a specific protector against cancer trauma symptoms in adults [20]. The results of the current study emphasize the relationship between stress management strategies and psychological adaptation to cancer. Among the patients examined, the strategies of actively coping related to less experienced stress. With increasing stress intensity, the patients withdrew their efforts and more frequently used strategies focused on avoidance behaviours. Olivia et al. studied the psychosocial needs of gynaecological cancer survivors in a group of 45 patients, contributing to the evaluation of the Cancer Survivors Unmet Needs measure. Linear regressions showed that anxiety, functional well-being, post-traumatic stress, and emotional well-being accounted for $40.7 \%$ of variance in fear of recurrence, with emotional well-being being the strongest predictor [21]. Other studies identified neuroticism as the strongest predictor of cancer-related worry along with continuing cancer-related symptoms. For depression, three personality dimensions (neuroticism, conscientiousness, and agreeableness) were significant predictors [22]. Rachel et al. examined associations between illness representation dimensions specified by the self-regulation model, coping and mood in 61 recently diagnosed gynaecological cancer patients. Support was found for a possible path whereby higher denial and avoidant coping might mediate the relationships between the cyclical timeline and illness coherence representations and more negative mood [23]. Costanzo et al. conducted a study to compare coping strategies and quality of life in two groups of patients with gynaecological cancer. The study showed that patients who underwent chemotherapy at an advanced disease stage more often used engagement and avoidant strategies, including active coping, seeking social support, and mental disengagement, compared to the reference group with a less progressed disease and did not receive chemotherapy, [14]. In other studies conducted by Pereira et al., patients with a higher use of the coping styles of anxious preoccupation, helplessness-hopelessness and cognitive avoidance reported a worse quality of life [15]. Shapiro et al. studied the relationship between emotional adjustment and a number of coping styles and strategies in a group of 283 oncological patients. Their results showed that there were associations between poor adjustment and emotional processing, and between good adjustment and hope, benefit finding, and cancer-related social support [16]. In the presented study, support from family and friends played a significant role. The results of a study by Simonelli et al. showed a high frequency of unmet support needs, particularly in the psychological, physical, and practical domains. Additionally, disparities in levels of support needs were found to be dependent on income and minority status [17]. Other studies have shown that gynaecological cancer survivors and health provider personnel share common ground as human beings, since shyness and openness are basic human phenomena [18]. In the current study, the most important determinant of the constructive style of coping with disease was the Positive Revalidation strategy, whereas the strategy of Acceptance was a determinant of the destructive style. This is a prerequisite for developing coping strategies to protect women from the negative effects of experienced traumatic events. In conclusion, it can be stated that the use of many different strategies in stressful situations gives some elasticity in coping and gives better mental adaptation to patients with cancer.

\section{CONCLUSIONS}

1. High levels of stress were reported in most of the gynaecological cancer patients surveyed, which means that the majority of patients assess their own disease-related life situation as stressful and over-burdensome.

2. Women facing cancer differ in their styles of coping with illness. They more often use a constructive style in the fight against cancer, which is more beneficial than passiveness and resignation.

3. Cancer patients who are able to actively identify themselves with the ways of adapting to cancer have a much greater exposure to task-oriented coping strategies and emotionally focused coping strategies.

4. The Positive Revalidation strategy was the most significant predictor of a constructive style of coping with illness, while the Acceptance strategy was the predictor of a destructive style.

5. There is a growing need to develop the ability to cope with stress in oncologically- treated women, and to offer them specialized psychological support.

\section{REFERENCES}

1. Juczyński Z, Ogińska-Bulik N. Narzędzia pomiaru stresu i radzenia sobie ze stresem. Warszawa, Pracownia Testów Psychologicznych, 2009.

2. Selye H. Tamed stress. Warszawa, Państwowy Instytut Wydawniczy, 1978.

3. Lazarus RS, Folkman S. Stress, appraisal and coping. Now York, US: Springer Publishing Company; 1984.

4. Heszen I. Psychologia stresu. Warszawa, PWN, 2013.

5. Folkman S. Personal control and stress, and coping processes: A theoretical analysis. J Pers Soc Psychol. 1984; 6(4): 839-852.

6. Sygit-Kowalkowska E. Radzenie sobie ze stresem jako zachowanie zdrowotne człowieka - perspektywa psychologiczna. Hygeia Public Health 2014; 49(2): 202-208.

7. Mroczkowska D, Białkowska J. Style radzenia sobie ze stresem jako zmienne determinujące jakość życia młodych dorosłych. Med Og Nauk Zdr. 2014; 20(3): 265-269.

8. Juczyński Z. Narzędzia pomiaru w promocji i psychologii zdrowia. Warszawa, Pracownia Testów Psychologicznych, 2009.

9. Parker JDA, Endler NS. Coping with coping assessment: A critical review. Europ J Person. 1992; 6: 321-344. 
10. Carver CS, Scheier MF, Weintraub JK. Assessing coping strategies: A theoretically based approach. J Pers Soc Psychol. 1989; 56(2): 267-283.

11. Carver CS, Scheier MF. Situational coping and copingdispositions in a stressful transaction. J Pers Soc Psychol. 1994; 66(1): 184-195.

12. Watson M, Greer S, Young J, Inayat Q, Burgess C, Robertson B. Development of a questionnaire measure of adjustment to cancer: the MAC scale. Psychol Med. 1988; 18(1): 203-209.

13. Watson M, Santos dos M, Greer S, Baruch J, Bliss J. The Mini-MAC: Further Development of the Mental Adjustment to Cancer Scale. J Psychosoc Oncol.1994; 12(3): 33-46.

14. Costanzo ES, Lutgendorf SK, Rothrock NE, Anderson B. Coping and quality of life among women extensively treated for gynecologic cancer. Psychooncology.2006; 15(2): 132-42.

15. Pereira MG, Baia V, Machado JC. Coping and quality of life in patients with skin tumors in the follow-up stage: The mediating role of body image and psychological morbidity. J Psychosoc Oncol. 2016; 34(5): 400-12.

16. Shapiro JP, McCue K, Heyman EN, Dey T, Haller HS. Coping-Related Variables Associated with Individual Differences in Adjustment to Cancer. J Psychosoc Oncol. 2010; 28(1): 1-22.

17. Simonelli LE, Pasipanodya E. Health Disparities in Unmet Support Needs of Women with Gynecologic Cancer: An Exploratory Study. J Psychosoc Oncol. 2014; 32(6): 727-734.
18. Sekse RJ, Råheim M, Gjengedal E. Shyness and openness--common ground for dialogue between health personnel and women about sexual and intimate issues after gynecological cancer. Health Care Women Int. 2015; 36(11): 1255-69.

19. Czerw AI, Religioni U, Deptała A, Walewska-Zielecka B. Assessment of pain, acceptance of illness, adjustment to life with cancer, and coping strategies in colorectal cancer patients. Prz Gastroenterol. 2016; 11(2): 96-103.

20. Oniszczenko W, Laskowska A. Emotional reactivity, coping style and cancer trauma symptoms. Arch Med Sci. 2014; 24:10(1): 10-6.

21. Urbaniec OA, Collins K, Denson LA, Whitford HS, Gynecological Cancer Survivors: Assessment of Psychological Distress and Unmet Supportive Care Needs. J Psychosoc Oncol. 2011; 29(5): 534-551.

22. Deimling GT, Albitz C, Monnin K, Renzhofer Pappada HT, Nalepa E, Boehm ML, Mitchell C, Personality and psychological distress among older adult, long-term cancer survivors. J Psychosoc Oncol. 2017; 35(1): 17-31.

23. Gould RV, Brown SL, Bramwell R. Psychological adjustment to gynaecological cancer: Patients' illness representations, coping strategies and mood disturbance. Psychology\&Health. 2010; 25(10): 633-646. 